\title{
High Power Fuel Cell Simulator Using an Unity Active Power Factor Rectifier
}

\author{
J.C. Alfonso Gil ${ }^{1}$, J.J. Vague Cardona ${ }^{2}$, F.J. Gimeno Sales ${ }^{3}$, S. Segui-Chilet ${ }^{4}$, S. Orts Grau ${ }^{5}$, N. Muñoz Galeano ${ }^{6}$ \\ ${ }^{1-5}$ Department of Electronics Engineering \\ (I.Q.M.A.), Universidad Politécnica de Valencia \\ Campus of Vera - Camino de Vera s/n, 46022 Valencia (Spain) \\ Phone:+0034 963 876076, e-mail: jvague@dcom.upv.es, joalgi2@etsii.upv.es, fjgimeno@eln.upv.es, \\ ssegui@eln.upv.es, sorts@eln.upv.es \\ ${ }^{6}$ Department of Electrical Engineering \\ Universidad de Antioquia \\ Street 63, Number 53-108, Medellin (Colombia) \\ e-mail: nicolasm@udea.edu.co
}

\begin{abstract}
This paper proposes a high power fuel cell simulator built by means of an active power rectifier that works with unity power factor in the grid side. The Unity Power Factor Rectifier (UPFR) is controlled by a digital processor to produce in the dc terminals the electrical behaviour of commercial high power fuel cells (FC). The control used in the paper is based in the FC model developed in the paper. The UPFR control algorithms are explained in the paper and some simulated results are presented in the paper. The simulated results demonstrate the behaviour of the proposed system.
\end{abstract}

\section{Key words}

Ohmic Region, Active Rectifier, Space Vector Pulse Width Modulation (SVPWM)

\section{Introduction}

Fuel Cells are energy sources that produce electrical energy from electrochemical energy. Some heat energy is also produced during the conversion. FC seems to be a clean and friendly with environment at the same time that shows a higher energy performance that other energy sources currently in use. Reduction in the use of fossil fuels and in $\mathrm{CO} 2$ production, braking of the climatic changes and a energy sustainable system are the main characteristics related with the use of FC. Hydrogen is seen as the fuel for the next future.

The cost of FC is nowadays high. The use of real FC in R\&D laboratories demands some hardware around the FC unit: hydrogen tank, coolers, pressure regulators, installation of pipes for gases and liquids and so on. All these determining factors justify the development of FC simulators. These types of equipment show the same behaviour than real FC systems but are cheaper and its use requires fewer infrastructures. Some FC simulators are based in the use of a semi empirical equation. The evaluation of the semi empirical equation results in a voltage that is used as a reference voltage in the control circuit of a DC/DC switched converter [1-2]. Other simulators model the semi empirical equation using resistances, inductances, capacitances and voltage sources, obtaining at the output a signal that reproduce the FC behaviour [3-4]. In [5], FC models obtained from the semi empirical equation are compared/analyzed. The influence over the FC model of each parameter is studied. Work developed in [6] uses a FC single cell to obtain the $\mathrm{V} / \mathrm{I}$ working point for some specific operating conditions. The obtained V/I working point is then scaled by an algorithm to modelize the behaviour of a FC stack. This paper proposes a new FC simulation method based on a piecewise-linear equivalent model of the V/I curve in different regions. With this piecewise-linear equivalent model the behaviour of a stack is obtained.

The model obtained is used by the control of an active rectifier to produce in the dc output the FC stack behaviour. The dc energy needed in the output is obtained from the power network as three positivesequence fundamental currents, working with a power factor near to 1 an introducing the minimum non active powers in the electrical system. Fig. 1 shows the block diagram of the applications described in the paper. The use of a three-phase system reduce the voltage ripple in the dc capacitor and allows to use a smaller capacitance, improving the dynamic response of the systems respect other system that uses conventional rectifiers to produce the dc output voltage.

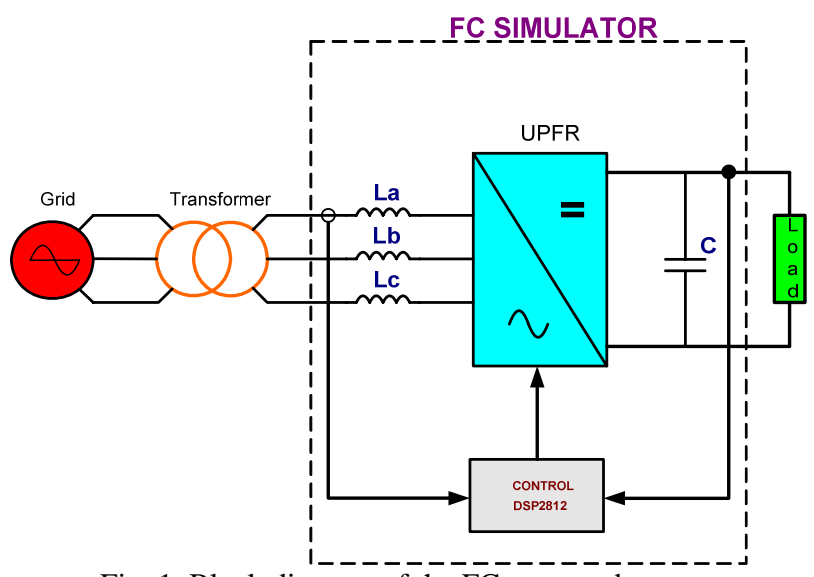

Fig. 1. Block diagram of the FC proposed system 


\section{FC model.}

Fig. 2 represents the V/I characteristic of a typical FC. It clearly corresponds to a non-linear system [2]. Three regions are defined in the FC V/I curve: activation region, ohmic region and concentration region. Typical FC operating points are in the ohmic region, where the behaviour is more linear than in the other regions, with a slow negative slope. In the ohmic region the FC output voltage is expressed as follows:

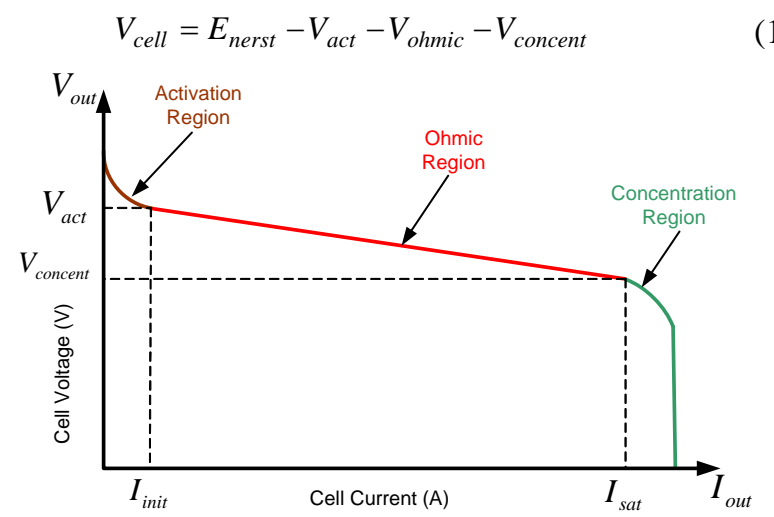

Figure 1.- FC V/I characteristic.

where:

$E_{\text {nerst }}$ is the FC thermo dynamical potential.

$V_{a c t}$ represent the voltage drop due to the activation of the anode and cathode terminals.

$V_{\text {ohmic }}$ is the voltage drop in the ohmic region due to the flow of protons through the electrolyte and the flow of electrons through the FC intrinsic resistances.

$V_{\text {concent }}$ is the voltage drop in the concentration region, where maximum currents are obtained in the FC output. In [1-3] are described the typical values of each of the terms that appears in (1) and an explanation of the characteristic of each region. Due the FC works in the ohmic regions, the activation regions is modelled by a constant voltage and the concentration region is modelled by a straight line with a high negative slope. With this linearization the equivalent model is simpler and easier to be implemented in a digital controller. The FC model used in the implementation is represented in Fig. 3

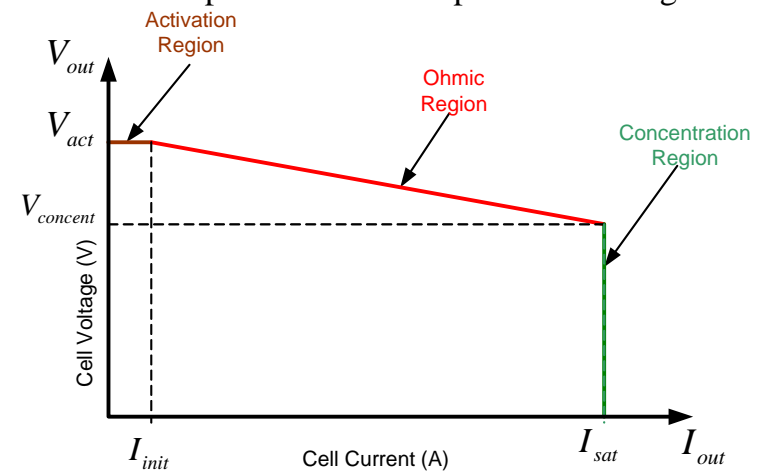

Figure 2.- Modelled FC V/I characteristic

The control of the FC simulator is implemented using the TMS320F2812 digital signal processor (DSP). This DSP implement the control of the UPFR and the FC model. The FC model algorithm is done using the next expressions.

$$
\text { if : } 0<I_{\text {out }}<I_{\text {ini }}
$$

$$
\begin{gathered}
V_{\text {out }}=V_{\text {act }} \\
\text { if }: I_{\text {ini }}<I_{\text {out }}<I_{\text {sat }} \\
V_{\text {out }}=\left(\frac{V_{\text {concent }}-V_{\text {act }}}{I_{\text {sat }}-I_{\text {ini }}} * I_{\text {out }}\right)-\left(\frac{V_{\text {concent }}-V_{\text {act }}}{I_{\text {sat }}-I_{\text {ini }}} * I_{\text {ini }}-V_{\text {act }}\right) \\
\text { if }: I_{\text {sat }}<I_{\text {out }} \\
V_{\text {out }}=0
\end{gathered}
$$

The FC simulator control uses the dc output current as $\left(I_{\text {out }}\right)$ a feedback signal to establish the FC operating region and verifying the previous conditions. Once the operating FC region is established, the FC output voltage $\left(V_{\text {out }}\right)$ is calculated and supplied in the dc output.

\section{FC simulator}

Figure 4 shows the block diagram of the FC simulator. The proposed system uses a three-phase active rectifier to simulate in the dc output the FC V/I characteristics. The use of three-phase active rectifiers, when are compared with single-phase active rectifiers, is preferred because output power can be higher and the dc capacitance is low due to the smaller dc voltage ripple of the three-phase converter. Active rectifier, compared with rectifiers based on the use of thyristors and diodes [1-2;6], are preferred because the utility power factor can be maintained in values near to 1 and do not demand non-active powers to the power network. With the use of an active rectifier is avoided the use of one of the DC/DC converters used in [1], improving the dynamic response of the system and the global performance. A Space Vector Pulse Width Modulation (SVPWM) technique is used to obtain the control signal of the IGBTs. Currents and voltages in the ac side of the simulator are measured and converted to dq coordinates. Current in the direct axis (Id) and in the quadrature axis (Iq) are used by the UPFR control. Several current control techniques are described in [7-8]

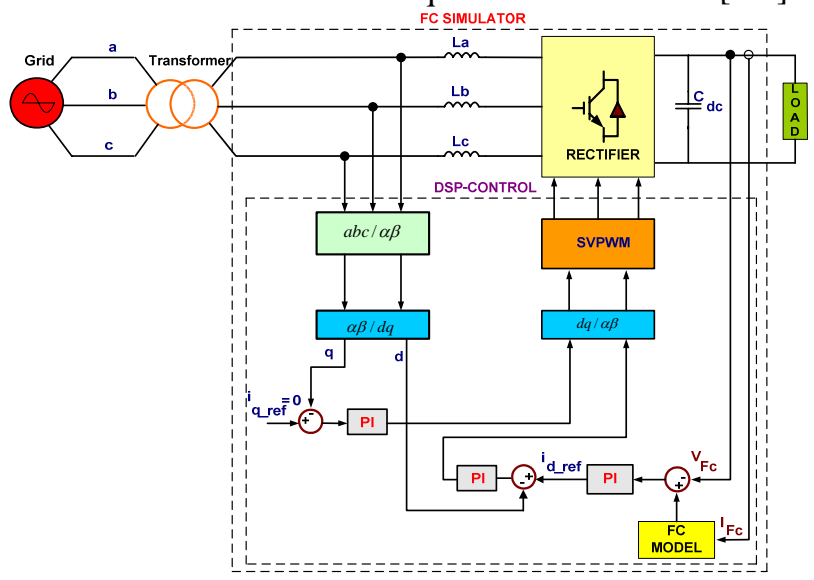

Figure 3.- FC simulator block diagram.

The dc output current is the input signal to the FC model block ((2)-(4)) and its output is the FC output voltage that correspond to that current. The error signal obtained with the comparison of the reference FC voltage and the measured FC voltage is the input signal to a PI regulator. The output of PI block show in Fig. 4 is one of the current reference signals of the UPFR.

To determine the necessary input active power the value of $I_{d}$ calculated from the input ac currents, is compared with the reference current for the direct axis obtained at 
the output of PI1. The error signal, through a PI regulator (PI2 block) produce one of the signals needed to control the UPFR. In order to consume only active power from the power network, $I_{q}$ reference is established equal to 0 , ensuring that the FC simulator works with unity power factor in the power network side. The comparison with $I_{q}$ calculated from the input ac currents is the error signal that uses a PI regulator (PI3 block) to obtain the other signal needed to control the UPFR. The signals obtained in $d-q$ coordinates are used to obtain the IGBT control signal, using a SVPWM modulator.

The block diagram of Fig. 4 is implemented in Matlab/Simulink, being represented in Fig. 5. The grid block produces three direct-sequence voltages with a frequency equal to $50 \mathrm{~Hz}$ and an rms voltage equal to 230 $\mathrm{V}$

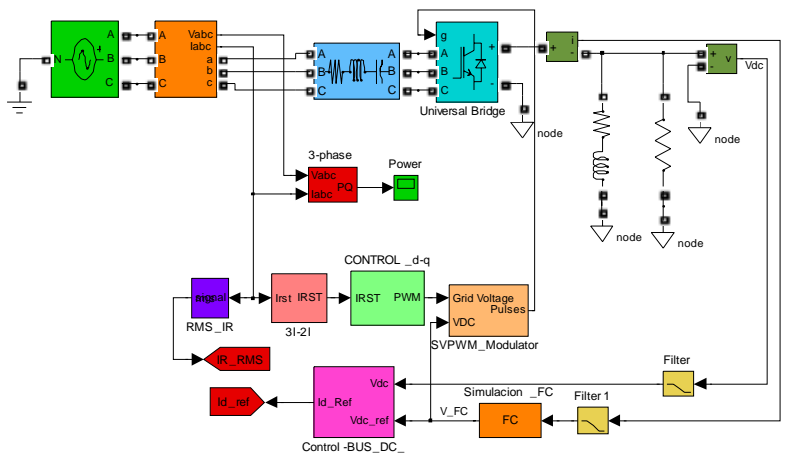

Figure 4.- Block diagram of the Simulink model.

Fig. 6 shows the block diagram of the subsystem "DC bus control", that implements the control of the dc voltage in the dc output terminals of the UPFR. Quality of the figure

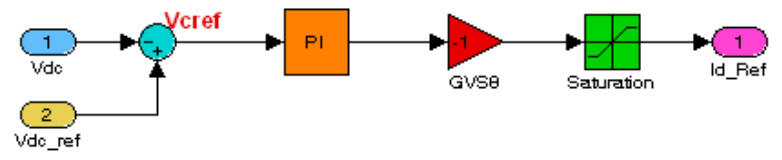

Figure 5.- Block diagram of the dc bus control subsystem.

Fig. 7 shows the block diagram of the subsystem "d-q control”. Quadrature and zero-sequence current references are set to zero because no reactive power is demanded by the UPFR and the power section work with a three-phase three-wire electrical system, without neutral wire. The reference current in the direct axis and the phase currents are the inputs to this subsystem.

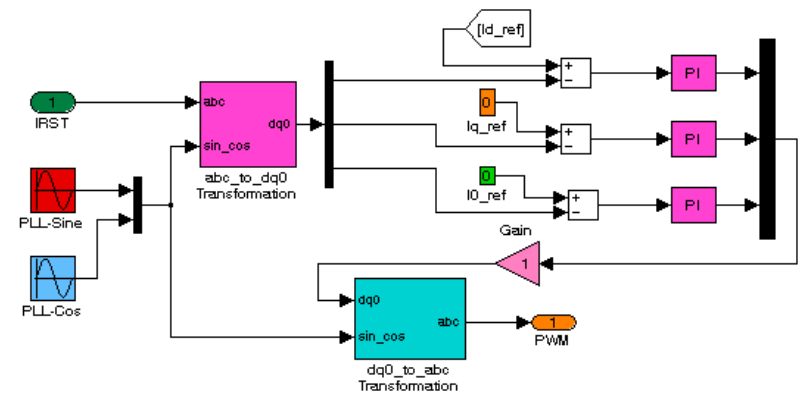

Figure 6.- Block diagram of the control d-q subsystem.

The subsystem "FC" uses a Matlab S-fucntion block, in which (2)-(4) are programmed. As can be seen in Fig. 5, the subsystem uses the dc load current to obtain the reference voltage that corresponds to the FC characteristic equations. The number of cells that constitute the FC stack is defined in this function, so the characteristics of the stack are defined on the basis of the single-cell model.

\section{Simulated Results.}

The simulation of the single-fuel cell is done using the block diagram showed in Fig. 8. The FC model follows (2)-(4), using the correct values for a single-cell. The load varies between $0 \mathrm{~A}$ to $80 \mathrm{~A}$ in less than $2.5 \mathrm{~s}$ (Fig. 10). The V/I characteristic of the single-cell for the programmed load is represented in Fig 10

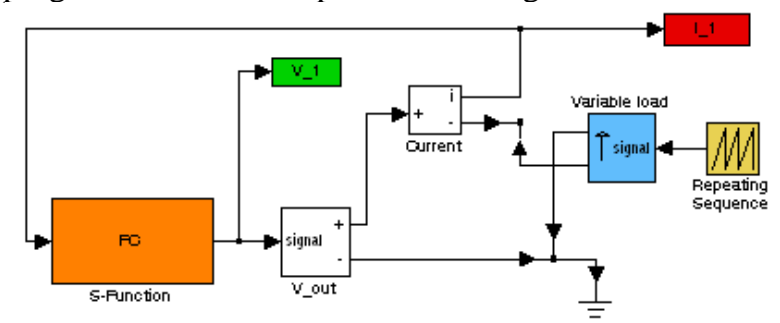

Figure 7.- Block diagram of the sub circuit used to obtain the V/I characteristic of a single-cell.

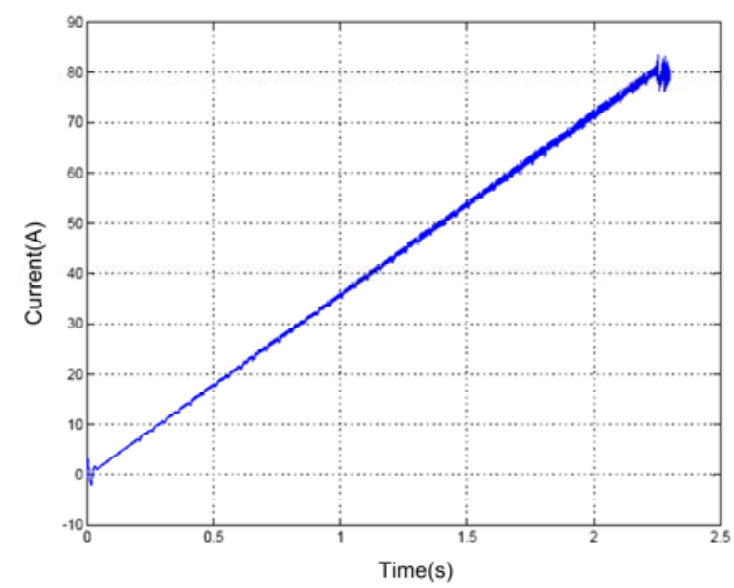

Figure 8.- Output current demanded by the programmable dc load during the test of the FC simulator dynamics.

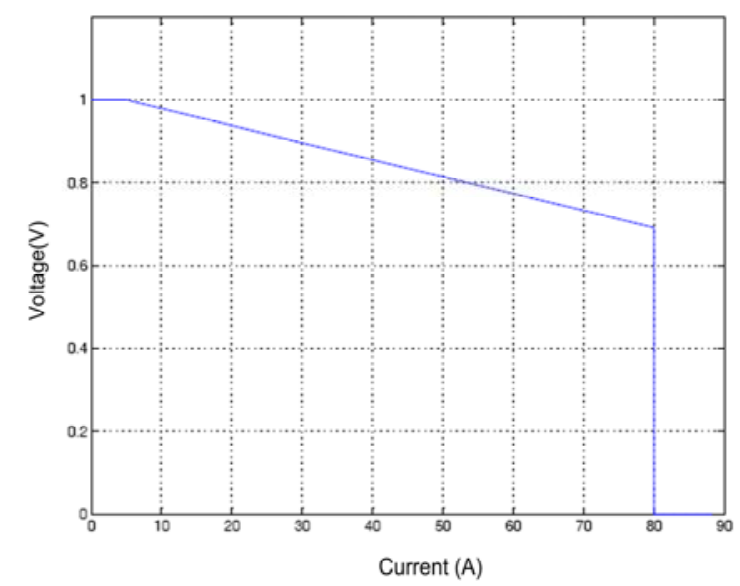

Figure 9.- V/I characteristic of a single-cell.

Table I defines the main parameters and component values used during the FC simulation using the UPFR. Fig. 11 shows the V/I characteristic obtained at the output of the FC simulator for the load variation showed in Fig. 
9. The maximum power is equal to $5.6 \mathrm{~kW}$, with a maximum power point voltage $\left(V_{M P P}\right)$ equal to $70 \mathrm{~V}$ and with a maximum power point current (IMPP) equal to 80 A.

TABLE I. - Values used during the simulations.

\begin{tabular}{|l|l|}
\hline Parameter & value \\
\hline Switching frequency & $10 \mathrm{kHz}$ \\
Input ac voltage (rms) & $24 \mathrm{~V}$ \\
AC input inductance & $600 \mu \mathrm{H}$ \\
Output maximum power & $5.6 \mathrm{~kW}$ \\
Output dc voltage range & $70-100 \mathrm{~V}$ \\
Output dc current range & $5-80 \mathrm{~A}$ \\
DC capacitance & $4.4 \mathrm{mF}$ \\
\hline
\end{tabular}

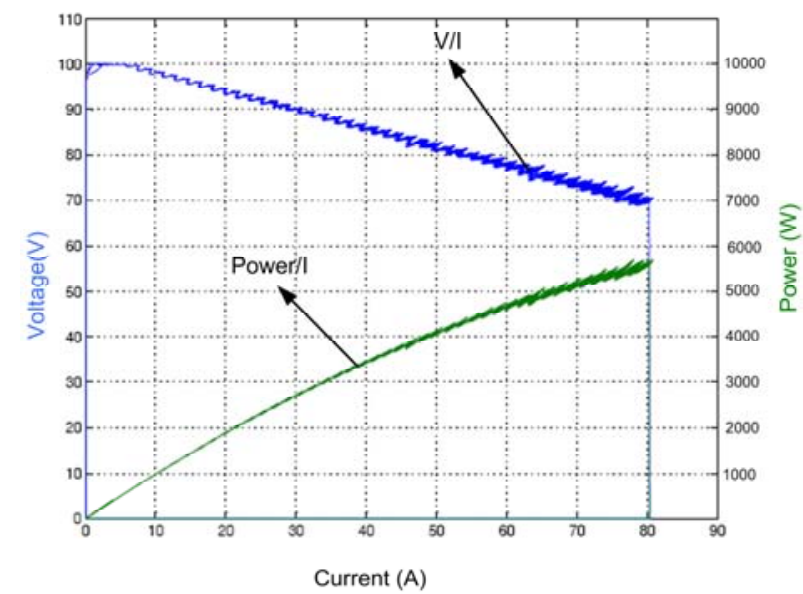

Figure 10.- FC V/I and FC Power/I characteristics obtained via simulation

Fig. 11 shows how the proposed system simulates the behaviour of the FC, with a high accuracy/precision and following the curve showed in Fig. 10 for a single-cell. The voltage in the activation region is constant (left side of the V/I characteristics included in Fig. 11). The ohmic region starts when the FC supplies an output current higher than $5 \mathrm{~A}$. In the ohmic region the V/I curve drops following (3). The behaviour in the ohmic region depends on the FC under simulation: maximum and minimum values of voltage and current supplied by the FC.

Fig. 12 shows the response time of the FC Simulator when a load step is programmed. The load current varies from 11 A to 50 amperes and the FC simulator needs less than $30 \mathrm{~ms}$ to achieve the new operating point. The FC voltage dynamics is better than the one of the current, with an under voltage smaller than the $10 \%$ of the maximum output voltage.

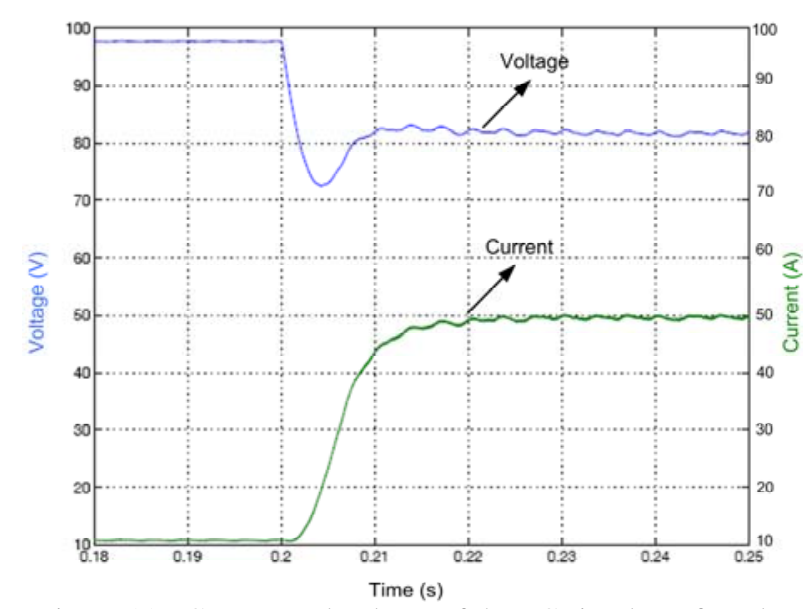

Figure 11.- Current and voltage of the FC simulator for a load transition.

The proposed FC simulator shows a response time $(<30$ $\mathrm{ms}$ ) that is much better than the typical response time of real FC (around 1 to 2 seconds). If a smaller response time is needed, the parameters that had to be modified are the followings:

- $\quad$ Reduce the sampling time of the S-function that includes the FC model.

- $\quad$ Reduce the sampling time of the UPFR current acquisition unit.

- $\quad$ Reduce the dc bus capacitance.

- Modify the parameters of the dc voltage control loop (PI).

The FC simulator can be programmed with a higher response time. The increase of the response time is obtained by software, through the monitor system that controls the FC simulator. New sampling times and new PI parameters are calculated to reproduce the desired FC dynamics.

During all the simulations the current THD is below 1.8 $\%$ in all cases.

\section{Conclusions.}

A new FC simulator is proposed in the paper. Small current THD in the power network and unity power factor are some of the advantages over other FC simulators. To obtain these two features a space vector PWM technique is used in the control of the UPFR joint with a high switching frequency. A FC piecewise linear equivalent model is developed in the paper. The FC simulator is modelled using Simulink. The most important blocks of the FC simulator are described.

Simulated results for a single-cell and for a FC stack are compared via simulation. Dynamic response of the system is studied for a large load transition, showing a better behaviour that the obtained with commercial FC. The results demonstrate that with the proposed FC simulator the voltage/current and power/current characteristics of commercial FC can be obtained in the dc output terminals of the UPFR. The use of the proposed simulator allow the development of other power converters needed in electrical systems generators based on FC without the waste of money needed to use real FC (fuels, pipes, the FC, pressure controls and so on). 


\section{Acknowledgement}

This work is supported in part by IMPIVA (Comunidad Valenciana - SPAIN). The project is supported by the Electrical Technology Institute in collaboration with the Politechnic University of Valencia and the Jaume I University of Castellón.

\section{References}

[1] Jeferson M. Corréa, Student Member, IEEE, Félix A. Farret, Jonas R. Gomes, and Marcelo Godoy Simoes, Senior Member , IEEE. "Simulation off FuelCell Staks Using a Computer-Controller Power Rectifier With the Purposes of Actual High-Power Injection Applications”.

[2] Tae-Won Lee, Byoung-Kuk Lee, Su-Jin Jang, Sung-Ho Kim, Chung-Yuen Won. Dep. Of information \& communications Engeneering, SungKyunKwan University, Suwon, 440-746, Korea. "Development of a 3Kw Fuel Cell Generation System with a Active Fuel Cell Simulator: Topology, Control, and Desing”.

[3] Jeferson M. Corréa, Student Member, IEEE, Felix A. Farret, Luciane N. Canha, , and Marcelo G. Simaóes, Senior Member, IEEE. “ An Electrochemical-Based, Fuel-Cell Model Suitable for Electrical Engineering Automation Approach”.

[4] Caisheng Wang, Student Member, IEEE, M. HasHem Nehrir, Senior Member, IEEE, and Steven R. Shaw, Member, IEEE. "Dynamic Models and Model Validation For PEM Fuel Cell Using Electrical Circuits”.

[5] Jeferson M. Corréa, Student Member, IEEE, Felix A. Farret, Vladimir A. Popov,and Marcelo G. Simaóes, Senior Member, IEEE. "Sensitivity Analysis of the Modeling Parameters Used in Simulation of Proton Exchange Membrane Fuel Cell”.

[6] Martin Ordonez, M. Tariq Iqbal and John E . Quaicoe. Memorial University of Newfoundland Faculty of Engineering \& Applied Science St. Jonh's, Newfoundland, Canadá. “A Novel Fuel Cell Simulator”

[7] KAZMIERSKOWSKI, M., and MALESANI, L., "Current control techniques for three phase voltage source PWM converters". IEEE Transactions on industrial electronics, Vol. 45, No. 5, October 1998, pp. 691-701.

[8] S. Buso, L. Malesani, . Mattavelli Comparison of Current Control Techniques for Active Filter Applications; IEEE Transactions on industrial electronics, Vol. 45, No. 5, October 1998, pp. 722-729. 